\title{
Short-term absence from industry I Literature, definitions, data, and the effect of age and length of service
}

\author{
P. FROGGATT \\ Department of Social and Preventive Medicine, The Queen's University, Belfast
}

Froggatt, P. (1970). Brit. J. industr. Med., 27, 199-210. Short-term absence from industry. I. Literature, definitions, data, and the effect of age and length of service. This, with two subsequent papers, comprises the first extensive study directed only to short-term absence from industry, an entity common in all branches of organized work and now one of the greatest personnel problems of an industrial society.

This first paper reviews the literature and background of industrial absence, describes the sources of the data and the groups for study, defines terms used throughout, discusses the rationale of the selection criteria, and examines the effect on the numbers of one-day and two-day absences of age and length of service in the organization.

The observations are from two light engineering works and two government departments and cover in all some $\mathbf{2} 300$ male and female personnel, both salaried and hourly-paid, over periods of up to seven years. Twenty study groups were identified for the analyses, each comprising members of similar 'works centre', sex, supervisory grade, and marital status, who neither changed relevant status during the study period nor were absent for more than 65 days in any year. This stringency in delimitation enhanced the validity of the conclusions drawn by $(a)$ ensuring necessary homogeneity for crucial variables, and (b) permitting examination of the consistency of the results over groups and organizations.

Multiple regression analysis for the effect of age and length of service on short-term absence showed that, generally, length of service had no effect but that age was (weakly) negatively linearly associated with the number of one-day absences but independent of the number of two-day absences. Transforming the skewed dependent variates to normal functions for completely valid analysis had no important effect on these results, which were also confirmed by data from a longitudinal study in one company. This association between age and one-day absences was too weak (more than $90 \%$ of the variation in the latter was unattributable to linear regression on the former) to be of executive importance but it is relevant to the validity of inferences from curve-fitting analysis presented in a later paper.

Much has been written about absence from work taken in spells of three or more days but little about shorter spells, possibly because they are variously treated in industrial sick-pay schemes and do not ordinarily qualify for national insurance benefit. Nevertheless, short-term absence is a pressing problem and occurs in all branches of industry.

In this and two subsequent papers I examine the numbers of one-day and two-day absences taken by individuals in two industrial concerns and in government service in Northern Ireland with reference to (a) their associations with certain social, biological, and industrial factors (Froggatt, 1970c), and (b) their distributions among personnel particularly in so far as these can be tested against expectation on several plausible hypotheses (Froggatt, 1970d). 
These papers are based on a lengthy thesis (Froggatt, 1967) and substantial compression of material and omission of many results has been necessary, but as far as possible the most important information is retained.

This paper reviews the literature, defines terms, describes the data, delimits the groups for study, and examines the relationship between short-term absence and age and length of service in the organization. A full discussion of all three papers is given in the third (Froggatt, 1970d) though short discussions and summaries complete the first two.

\section{Background and literature}

Short-term absence, i.e., failure to report for work on one or two consecutive days, requires a considered decision by the employee himself. In its widest context it is an integral of a pattern of discontinuous work, the roots of which lie deep in pre-industrial society and which can be traced forward to the present day (Thomas, 1964). Much attention has been paid to the reasons for irregularity of attendance in medieval craft trades (Salzman, 1952) and early industry (Furniss, 1920; Langenfelt, 1954; Coats, 1958): in general, and omitting enforced absence when work was not available and certain special situations (e.g., children often stayed from work when their parents 'particularly wanted them' (Select Committee, 1816, p. 82) ), irregularity was attributed to the difficulty in orientation to a discipline of continuity and regularity in working hours, allied to 'new' philosophies and economic theories, of people to whom these were alien (Kerr, Dunlop, Harbison, and Myers, 1962). To achieve the discipline the factory system required, employers sought to make labour - whom they viewed as hedonistic - obedient by, in the shorter term, inducements and deterrents and, in the longer term, by inculcating a new ethos of work, order, obedience, economic outlook, and morality. The science of management hardly existed until the appearance of Babbage's (1832) book (which ran to three editions in its first year) and publications largely ignored labour relations while detailing the economic use of machinery and raw materials. Management was mainly pragmatic and sought simply 'uniform good order and proper authority' (J.M., 1832) or, like Josiah Wedgwood, to make 'such machines of the men as cannot err' (McKendrick, 1961). There were exceptions: Robert Owen reduced absence and increased production by shortening working shifts (Select Committee, 1816, p. 89), and the great proprietors, Arkwright (Ashton, 1955), Boulton (Roll, 1930), and Owen himself (Cole, 1925), sought to improve morale and instil esprit de corps by appeal to employees' sensibilities; but these were unusual. Against this background short-term absence was widespread and an intrinsic part of human behaviour and reaction to conditions tempered by tradition and social culture.

During the present century more specific causes have been sought. In addition to bona fide sickness, authors have identified working conditions (Vernon, Bedford, and Warner, 1928; Vernon and Bedford, 1931; Bedford and Warner, 1931), fatigue (Loveday, 1917), general morale (Loveday, 1917; Vernon and Rusher, 1920; Smith and Leiper, 1936), age, sex, and marital state (Wyatt, Marriott, and Hughes, 1943; Wyatt, 1945; London Transport Executive, 1956), and method of payment, occupation, size of working group, and level of wages (London Transport Executive, 1956; Shepherd and Walker, 1958) as contributing to 'absenteeism' and to absences described as 'short-term', 'casual', 'avoidable', 'voluntary', 'without permission', 'uncertificated', and 'uncertified'. (For reviews see: Acton Society Trust, 1953, 1957; Behrend, 1959; Lokander, 1962; Froggatt, 1967.) Such diversity, however, may simply indicate changes in attitudes and interests of researchers as the century has progressed rather than any change in causes or in the short-term absence pattern. Thus a high level of absence on Mondays can be traced from the early observance of 'St. Monday' and 'St. Tuesday' (Fothergill, 1796; Select Committee, 1816, pp. 234, 259; Factories Inquiry Commission, 1833, B.1, p. 16; Report of Commissioners, 1842, pp. 123-4; 1843, p. 77 et seq; Rollins, 1922; Pollard, 1963) through later industrial society ('St. Monday is] that canker eternally eating at the root of the prosperity of the Five towns' (Bennett, 1902) - with 'Pay Monday' (Select Committee, 1873, Q.216), 'Colliers' Monday', 'Drunken Tuesday' and even (for the fortnightly paid) 'Lazy Wednesday' (Buzzard and Liddell, 1963, p. 21) in the colliery and mining industries, to salaried staff in the present century (Hart, 1922) and the contemporary 'Blue Monday' (Baldamus and Behrend, 1950; Behrend, 1951). Today short-term absence is attributed either to 'sickness' or to 'other factors' (and their interaction) but the relative importance of each is unknown.

Numerical data are sparse. Early records generally specified only 'number sick at present', i.e., the number 'absent sick' at roll-call on a particular day (Select Committee, 1816; Froggatt, 1968a), while companies which kept fuller records usually either ignored short-term absences (Factories Inquiry Commission, 1834, pp. 80-1) or pooled them with longer absences when calculating indices of 'sickness', e.g., the East India Company (London Establishment) (Factories Inquiry Commission, 1834, pp. 48-9; Froggatt, 1968b). Only exceptionally were short-term absences recorded but the data are either unreliable (e.g., those from Samuel Greg's 'Low Mill' at Caton were compiled from employees' 
statements (Factories Inquiry Commission, 1834, App.D.1, p. 150) ) or else it is impossible to distinguish accurately spell-length (e.g., shore establishment at H.M. Dockyard, Plymouth, had frequency distributions of sickness recorded but only by 0,1 , 2 . . . total days per year (Factories Inquiry Commission, 1834, p. 57)). Data from later in the century are equally unrevealing: ad hoc studies largely ignored short-term absences (see Froggatt, 1967, for review), benefit societies did not ordinarily meet short-term claims (Neison, 1845, 1846, 1882; Friendly Societies, 1852-3, 1896; Watson, 1903, 1910; Rusher, 1922), and the 'time-registers' which the factory inspectorate issued (from October 1836) specified the hours worked by children and young persons only as a group and not individually (Inspector of Factories, 1837, pp. 36 et seq.) ${ }^{1}$

Official reports still evidenced the prevalence of 'irregularity of attendance' (Select Committee, 1873, under heads) and 'absenteeism' (Departmental Committee, 1907, QQ. 1956, 2718, 2789, 4898, $10,553)$ - supported, by 1907 , by some numericaldata from the coal-mining industry (Departmental Committee, 1907, First Rep. Pt. II, App. C: Pt. III, App. 7) - but only later did Hart (1922), Hill (1929), Smith and Leiper (1936), Wyatt et al. (1943), Wyatt (1945), Buzzard and Shaw (1952), Fortuin (1955), London Transport Executive (1956), Kahne, Ryder, Snegireff, and Wyshak (1957), Gordon, Emerson, and Pugh (1959), Simpson (1962), and Taylor (1969) classify data so that 'short-term' absences (sometimes including spells of three days) or one-day (or shift) and/or two-day (or shift) absences could be distinguished. ${ }^{2}$ Of those who analysed their data, Wyatt (1945), London Transport Executive (1956), Kahne et al. (1957), and Taylor (1969) showed short-term absences (as measured) to decrease with age, though Simpson's (1962) results for schoolteachers refutes this; the first two showed such agespecific absence to be higher for married than for single women; while Kahne et al. (1957) and Taylor's (1969) results indicate differences between salaried and hourly-paid personnel. Hart (1922),

'The previous system of 'time-forms' and 'time-books' legally though seldom de facto in force from January 1834 and which were to specify for each child and young person inter alia all his 'sickness absences' (Inspector of Factories, 1834 , pp. 30-1) - had been abandoned in September 1836 as impracticable (Inspector of Factories, 1837, p. 33). Only limited data, from eight mills in the Preston area, seem to have been published (Inspector of Factories, 1834, p. 52 et seq.) but are uninformative on short-term absence.

2The Post Office produces, annually, information giving frequency distributions of spells of absence by duration including 1, 2 . 7 days (Marsh, 1967), but this is for internal use. Similar data of Norris (1951) are on schoolchildren. The National Coal Board distinguishes 'voluntary' and 'involuntary' absenteeism but not on the basis of spell length (Ministry of Fuel and Power, 1948-9). and generally also Taylor (1969), found absences of one and two days' duration to start most commonly on a Monday.

Little is therefore known about the statistics of short-term absence per se. To study it further, oneday and two-day absences are separately distinguished in this study; 'number of one-day absences' and 'number of two-day absences' are used as variates and the properties of each are examined in defined groups of personnel. These units have not previously been selected for analysis and it is hoped that this approach may contribute to an understanding of an entity which is now one of the greatest single personnel problems of an industrial society.

\section{Definitions of terms}

The following descriptions relate to the larger of the two industries (company G) which provided the principal figures for analysis but, except where specifically noted, they can be accepted as applicable to the smaller company (company $\mathrm{M}$ ) and, where relevant, also to government service.

Centre That part of the industry in which employees work in similar or related occupations. An employee who changed his centre was classified for that year in the centre in which he spent most time. 'Centre unit' (q.v.) describes a group of centres pooled for the analyses.

Supervisory grade A category indicating an employee's degree of supervisory responsibility. Two grades only were recognized - junior and senior. Those in the former do not exercise any regular authority: those in the latter exercise some; they are generally foremen, charge-hands, section leaders, supervisors, and superintendents.

Marital status Only 'single' and 'married' classes were distinguished; widows, widowers, and divorcees were classed as 'married'. Personnel and medical records ordinarily gave the marital status only at the time of employment (though for women a change of name during employment was often recorded) and information was up-dated by noting changes in PAYE coding, by checking a wedding present subscription list (which covered most weekly-paid staff in company $G$ ), and by questioning personnel.

Length of service Ordinarily this was taken as the number of completed years of continuous service with the company on the first day of the year in question. In the (very) few cases of promotion of a works employee to the staff (q.v.), length of service was measured from the date of promotion. Recording procedures necessitated the following expedients when employment had been interrupted: for staff - for temporary resignations, or redundancies sufficiently long to lose accrued sick-pay privileges (ordinarily about nine months), length of service was counted from the date of re-employment; for works personnel often the only date recorded was the one following the last cessation of employment. 
Employment class This denotes the two basic classes of employee - staff, who are salaried; and works personnel, who are wage-earners. Inter alia the former, though not the latter, did not ordinarily lose income when absent except for protracted sickness.

Monthly-paid staff In company G, monthly-paid staff are executive grades who do not always have to account for their time-keeping: they were therefore excluded. In company $\mathbf{M}$, all grades above works personnel are monthly-paid (more exactly 'period-paid' every fourth Wednesday) and there were full attendance records for the groups considered here, which exclude higher executive and management grades. The civil service clerical grades (permanent staff) are monthly-paid and have full attendance records.

Weekly-paid staff These are exclusively employees in company G. Two types were distinguished: works staff, i.e., shop operatives (e.g., inspectors); and office staff, i.e., white-collar workers. They ordinarily participate fully in the company's ex gratia sick-pay scheme (q.v.).

Works personnel Only relevant in company $\mathbf{G}$, these are time-workers paid wages (on Friday) and under one hour's notice of termination of employment. They were not covered by an employer's sick-pay scheme and lost wages pro rata when absent (except for company business or a works accident) though on occasions ex gratia payments were made.

One-day absence This is an absence, for a half or an entire day, when the employee attended the whole of the preceding and succeeding working days (holidays, Saturdays, and Sundays are non-working days) other than absence on account of a labour dispute, company business, or sanctioned by a pass. All such absences, irrespective of alleged 'cause' (other than the exceptions given), were included.

Two-day absence This is an absence starting on Monday, Tuesday, Wednesday, or Thursday when the employee attended the previous working day and at least part of the following day but one, other than absence on account of a labour dispute, company business, or sanctioned by a pass.

Lateness Figures were collected from companies $\mathbf{G}$ and $M$ but only those from the former were sufficient for informative analysis. For staff, lateness was recorded as daily totals of minutes late but was generally only abstracted as weekly totals; for works personnel it was recorded by weekly totals of occasions late measured in units of 15 minutes, i.e., 20 minutes late was given as $1 \times 15,40$ minutes late as $2 \times 15$, etc.

Medical pass This is a permit to leave work, given exclusively on medical grounds by the medical department.

Works pass This is a permit to leave work and is given under the discretion of a foreman or supervisor and enables an employee to leave work before time without inviting disciplinary action.
Long-term sickness absence This convenient term is used for an 'absence attributed to sickness' of three or more days. Company $\mathbf{G}$ and the civil service require a medical certificate for such absences: company $M$ requires a certificate only for absences of four or more days.

Sickness taken In both companies this is the sum of one-day and two-day absences and long-term sickness absence: in the civil service one-day and two-day absences, if totalling not more than seven days in one year ('Whitley days'), are not ordinarily so aggregated unless they are certificated. 'Sickness taken' is the statistic used in calculating allowance for bənefit under the staff sick-pay schemes.

Sick-pay schemes Both companies operated, for staff employees, ex gratia sick-pay schemes. These provided for payment of full normal rates (after deduction of any entitlements under national schemes) from the first day of incapacity until the total of 'sickness taken' in the year reached two weeks (for less than 2 years of service), three weeks (for 2 to 3 years of service) up to variable maxima, and thereafter similar phased scales of half-pay. In the government service groups 'Whitley days' were not aggregated and full normal rates were paid generally for six months; thereafter each case was reviewed.

Accounting period This is 1 January to 31 December for company $\mathbf{G}$ and government service groups; 1 October to 30 September for groups from company M. For convenience, the accounting period (in company $\mathbf{M}$ ) for, say, 1 October 1958 to 30 September 1959 is designated '1959'.

\section{Description of sources}

Two light engineering companies in Belfast (companies $G$ and $M$ ) and two departments of the Northern Ireland government supplied the material for study. The main enquiry was in company G; material from company $\mathbf{M}$ and the civil service is less detailed and was collected mainly for subsidiary analysis.

\section{Company G}

This company employed on average some 7000 to 8000 persons during the period of the investigation (1955-59). The employees admitted for study were all those (about 1500 ) in six centres or centre units in one (the principal) factory - out of about one hundred centres in the company's five factories these centres being chosen because they covered staff and works personnel and supplied groups reasonably homogeneous for working conditions, skills, and jobs performed. The following facts were abstracted from each employee's attendance card for each year from 1955 to 1959: name, address, centre, clock number, year of data, sex, marital status (later checked - see above), supervisory grade, age, length of service, numbers of works and medical passes, date of leaving employment, total 
number of days off work, numbers of one-day and two-day absences by date (later converted to day of week and month of year), total minutes (for staff) and occasions (for works personnel) late, amount of sickness allowed on full- and half-pay (for staff); and, for 1957 and 1958 for employees in three of the six centre units, also lateness and works and medical passes by date (later converted to day of week and month of year); and in addition for employees in one centre unit for 1959, weekly totals (in hours) of overtime worked. During the period there was a down-turn in the company's business with redundancies, efforts to diversify were largely unsuccessful, comparatively few new persons were employed in the centres studied, and company morale appeared low.

\section{Company $M$}

This company has one factory in Northern Ireland and employed some 500 persons in 1952, rising to nearly 2000 in 1959 . Centre units were chosen for the same reasons as in company G, and only staff about 400 in 1959 - were studied. Similar items as for company $G$ were available from the attendance cards except the following: numbers of works and medical passes, lateness, and amount of overtime worked. During the period covered by the study (1953-59) there was a buoyant market for the company's products, a substantial increase in plant and jobs, good working conditions and terms of employment, and company morale appeared high.

\section{Government service}

In 1958 the Northern Ireland civil service employed 10282 staff, of whom 5564 were in the general service grades (Kidd and Park, 1960). Clerical staff (permanent) in these grades differed from staff in companies $\mathbf{G}$ and $\mathbf{M}$ : inter alia they were allowed seven 'Whitley days' per year, all females were single (q.v.), and the (monthly-paid) staff considered here were of grades which were weekly-paid in company $\mathbf{G}$ (all staff in company $\mathbf{M}$ were monthlypaid). The material relates to some 1000 staff in the clericalgrades of the general service staff (permanent) in two departments during 1959. The items available were: date of birth, marital status (men), date of entry to the service (one department only), date of leaving if during 1959, and dates of one-day and twoday absences - later converted to day of week and month of year.

\section{Selection of the study groups}

\section{Criteria of selection}

The observations were initially unselected within the centre units or departments chosen; all individuals in employment at the end of a year were originally admitted. These cross-sectional groups were, how- ever, inappropriate for many of the analyses. Selection had to be made, the criteria adopted being those which would produce the most valid 'study groups', particularly for examination by the discrete distribution methods to be used to test the formulated hypotheses of causation. These criteria are well known; in the present context they may be summarized as follows:

(a) each study group must be reasonably homogeneous for factors known or likely to have an effect on the short-term absence record;

(b) each member of a study group must be equally 'exposed to risk' of taking a one-day or two-day absence;

(c) within each study group ascertainment of short-term absences must be complete or, if incomplete, those ascertained should be a random selection of those actually taken;

(d) the period covered by the observations should be sufficiently long to ensure inter alia that the frequency distributions of one-day and two-day absences are of a convenient statistical form, i.e., can be readily transformed to a 'normal' distribution - and their fitting by theoretical models effected using computer programs with realistic restrictions; and

(e) the study groups should be sufficiently large for informative analysis and numerically of similar order so that equal weight can be attached to the findings in each group.

Fulfilling criteria $(a)$ to $(e)$ above imposes selection. This is not considered vital because even so-termed 'unselected' industrial personnel material is biased in many ways. Apart from self-selection before employment and imposed selection at pre-employment interviews, the principal selection factors (with respect to short-term absences) fall into the following four groups:

$(f)$ the employer may transfer or dismiss an employee whose short-term absences are excessive;

$(g)$ an employee, because of excessive short-term absences, may consider his job injurious to health or unsuitable on other grounds and seek transfer or leave employment;

(h) an employee's short-term absence record and his selection by management for transfer or redundancy are not always independent; and

(i) common factors may exist (apart from the actual short-term absence record) which make an employee more liable to take a one-day or two-day absence and at the same time to leave employment or be transferred.

The study groups

Company G The 12 centres selected were pooled to form the following six centre units: A and B (works personnel); C and D (works staff, except females in $D$ who are office staff); and $E$ and $F$ (office staff). 
Criteria (a) to (e) above were fulfilled as follows. For (a), eight groups for each of the six centre units A to $E$ were delimited representing all permutations of sex, supervisory grade (junior or senior), and marital status (married or single), three simple factors which the literature suggests may influence short-term absence, viz., junior single male (JSM), junior single female (JSF), junior married male (JMM), junior married female (JMF), senior single male (SSM), senior single female (SSF), senior married male (SMM), and senior married female (SMF). Employees who changed their marital status or supervisory grade during the period were excluded. For $(b)$, only persons in continuous employment over the period of study and who were absent for whatever cause for less than 65 working days in any accounting year during this period were admitted. (This period of 65 days is arbitrary. The annual mean number of one-day absences per person in the study groups ranges from 2.0 to 3.5 and so even absences up to 65 days should not reduce the 'exposure to risk' to an important extent. Excluding on less total absence would have no practical advantage and would further reduce the numbers available for study.) For (c), grades of employees not ordinarily accountable for their short-term absences were excluded. For $(d)$, a two-year period for one-day absences was generally adequate; for

\section{TABLE I}

TeST For Homogeneity OF THE FReQuency Distributions of SHORT-TERM ABSENCES between Centre Units Within Years

(a) JMM in Centre Units $E$ and $F, 1957$ and 1958

\begin{tabular}{|c|c|c|c|c|}
\hline \multirow{2}{*}{ No. of absences } & \multicolumn{2}{|c|}{1957} & \multicolumn{2}{|c|}{1958} \\
\hline & \multicolumn{2}{|c|}{$\underset{E}{C} \quad F$} & \multicolumn{2}{|c|}{$\begin{array}{c}\text { Centre units } \\
E\end{array}$} \\
\hline $\begin{array}{c}\text { One-day absences } \\
0 \\
1 \\
2 \\
3 \\
4 \\
5 \\
6+\end{array}$ & $\begin{array}{r}22 \\
12 \\
9 \\
8 \\
6 \\
2 \\
5\end{array}$ & $\begin{array}{r}11 \\
18 \\
12 \\
5 \\
4 \\
10 \\
8\end{array}$ & $\begin{array}{r}20 \\
12 \\
12 \\
10 \\
2 \\
5 \\
3\end{array}$ & $\begin{array}{r}15 \\
14 \\
10 \\
12 \\
5 \\
6 \\
6\end{array}$ \\
\hline \multicolumn{5}{|c|}{$\begin{array}{l}x^{2}(1957)=12.28, \text { D.F. }=6,0.10>P>0.05 \\
x^{2}(1958)=3.00, \text { D.F. }=5,0.70>P>0.50\end{array}$} \\
\hline $\begin{array}{c}\text { Two-day absences } \\
0 \\
1 \\
2 \\
3+\end{array}$ & $\begin{array}{r}32 \\
19 \\
9 \\
4\end{array}$ & $\begin{array}{l}24 \\
17 \\
17 \\
10\end{array}$ & $\begin{array}{r}38 \\
15 \\
4 \\
7\end{array}$ & $\begin{array}{r}29 \\
19 \\
9 \\
11\end{array}$ \\
\hline \multicolumn{5}{|c|}{$\begin{array}{l}x^{2}(1957)=6.20, \text { D.F. }=3,0.20>P>0.10 \\
x^{2}(1958)=4.34, \text { D.F. }=3,0.30>P>0.20\end{array}$} \\
\hline
\end{tabular}

(b) JSM in Centre Units $C, E$ and $F$, 1957 and 1958

\begin{tabular}{c|rrr|rrrr}
\hline \multirow{2}{*}{ No. of absences } & \multicolumn{3}{|c|}{1957} & \multicolumn{4}{|c}{1958} \\
\cline { 2 - 6 } & \multicolumn{3}{|c|}{ Centre units } & \multicolumn{4}{|c}{ Centre units } \\
& \multicolumn{1}{|c|}{$E$} & $E$ & $F$ & \multicolumn{1}{|c|}{$C$} & $E$ & $F$ \\
\hline One-day absences & & & & & & \\
$0-3$ & 16 & 15 & 37 & 13 & 12 & 37 \\
$4+$ & 10 & 3 & 13 & 13 & 6 & 13 \\
& & & & & & \\
\hline
\end{tabular}

$x^{2}(1957)=2 \cdot 68$, D.F. $=2,0.30>P>0.20$

$x^{2}(1958)=4 \cdot 30$, D.F. $=2,0.20>P>0 \cdot 10$

\begin{tabular}{c|rrr|rrr}
\hline Two-day absences & & & & & & \\
$0-1$ & 19 & 13 & 38 & 17 & 14 & 41 \\
$2+$ & 7 & 5 & 12 & 9 & 4 & 9 \\
\hline
\end{tabular}

$x^{2}(1957)=0.15$, D.F. $=2,0.95>\mathrm{P}>0.90$

$x^{2}(1958)=2.63$, D.F. $=2,0.30>\mathrm{P}>0.20$

(c) SMM in Centre Units $C, D$ and $F$, 1957 and 1958

\begin{tabular}{|c|c|c|c|c|c|c|}
\hline \multirow{2}{*}{ No. of absences } & \multicolumn{3}{|c|}{1957} & \multicolumn{3}{|c|}{1958} \\
\hline & \multicolumn{3}{|c|}{$\begin{array}{l}\text { Centre units } \\
C \quad D \quad F\end{array}$} & \multicolumn{3}{|c|}{$\begin{array}{l}\text { Centre units } \\
C \quad D \quad F\end{array}$} \\
\hline $\begin{array}{c}\text { One-day absences } \\
0-2 \\
3-5 \\
6+\end{array}$ & $\begin{array}{l}30 \\
24 \\
11\end{array}$ & $\begin{array}{r}11 \\
3 \\
3\end{array}$ & $\begin{array}{r}16 \\
10 \\
3\end{array}$ & $\begin{array}{r}28 \\
32 \\
5\end{array}$ & $\begin{array}{r}13 \\
2 \\
2\end{array}$ & $\begin{array}{r}15 \\
10 \\
4\end{array}$ \\
\hline \multicolumn{7}{|c|}{$\begin{array}{l}x^{2}(1957)=3.18, \text { D.F. }=4,0.70>P>0.50 \\
x^{2}(1958)=8.72, \text { D.F. }=4,0.10>P>0.05\end{array}$} \\
\hline $\begin{array}{c}\text { Two-day absences } \\
0-1 \\
2+\end{array}$ & $\begin{array}{l}48 \\
17\end{array}$ & $\begin{array}{r}13 \\
4\end{array}$ & $\begin{array}{l}18 \\
11\end{array}$ & $\begin{array}{l}53 \\
12\end{array}$ & $\begin{array}{r}13 \\
4\end{array}$ & $\begin{array}{r}22 \\
7\end{array}$ \\
\hline \multicolumn{7}{|c|}{$\begin{array}{l}x^{2}(1957)=1.58, \text { D.F. }=2,0.50>\mathrm{P}>0.30 \\
x^{2}(1958)=0.51, \text { D.F. }=2,0.80>\mathrm{P}>0.70\end{array}$} \\
\hline
\end{tabular}

the less frequent two-day absences, and for some sub-classifications of one-day absences, e.g., by the day of the week, a longer period was necessary. For (e), pooling of centres and centre units (see below) was planned so that the resultant groupings would be homogeneous - under $(a)$ to $(d)$ above - and (in company $\mathbf{G}$ ) would fall in the convenient range of 100 to 200 individuals.

There were 48 possible groups (JSM, JSF, etc. in each of centre units $A$ to $F$ ), 40 in practice because there were no females in two centre units. Four of these $40-$ JMM for centre units A, B, C, and $D$ - were sufficiently large for independent analysis. JMM for centre units E and F, JSM for centre units $C, E$, and F, and SMM for centre units $C, D$, and F 
(the very few SSM personnel were omitted) could be respectively pooled into three further groupings since all were staff and the distributions of shortterm absences over a two-year period in the centre units involved were not significantly (at $P=0.05$ ) dissimilar (Table $1(\mathrm{a}, \mathrm{b}, \mathrm{c}))$. It was necessary to pool all office staff centre units to obtain an adequate group of females though only after ensuring that the short-term absence experiences of married and single women were not significantly different (Table 2).

\section{TABLE 2}

Test for Homogeneity of the Frequency Distributions BETWEEN MARRIED (M) AND Single (S) Females in Pooled Centre Units (D, E AND F) WITHIN YeARS

\begin{tabular}{c|rr|rr}
\hline \multirow{2}{*}{ No. of absences } & \multicolumn{2}{|c|}{1957} & \multicolumn{2}{|c}{1958} \\
\cline { 2 - 5 } & \multicolumn{2}{|c|}{ Marital status } & \multicolumn{2}{|c}{ Marital status } \\
& $M$ & $S$ & \multicolumn{2}{|c}{$S$} \\
\hline One-day absences & & & & \\
$0-1$ & 13 & 37 & 16 & 30 \\
$2-3$ & 9 & 20 & 8 & 23 \\
$4+$ & 10 & 17 & 8 & 21 \\
& & & & \\
\hline
\end{tabular}

$\chi^{2}(1957)=1.03$, D.F. $=2,0.70>\mathrm{P}>0.50$ $x^{2}(1958)=0.84$, D.F. $=2,0.70>\mathrm{P}>0.50$

\begin{tabular}{c|rr|rr}
\hline Two-day absences & & & & \\
0 & 12 & 29 & 10 & 36 \\
1 & 12 & 26 & 17 & 25 \\
$2+$ & 8 & 19 & 5 & 13 \\
\hline$\chi^{2}(1957)=0.06$, D.F. $=2,0.98>\mathrm{P}>0.95$ \\
$\chi^{2}(1958)=3 \cdot 70$, D.F. $=2,0.20>\mathrm{P}>0.10$ \\
\hline
\end{tabular}

The resultant 12 groups, subsequently termed 'study groups', are composed and designated as set out below. Numbers of persons are in parentheses: the observations for G1 to G8 relate to the two-year period 1957-58; those for G9 to G12 relate to the four-year period 1955-58.

G1 (113) JMM centre unit A (works personnel)

G2 (123) JMM centre unit B (works personnel)

G3 (116) JMM centre unit C (works staff)

G4 (195) JMM centre unit $D$ (works staff)

G5 (132) JMM centre units $E$ and F (office staff)

G6 (94) JSM centre units C, E, and F (staff)

G7 (111) SMM centre units C, D, and F (staff)

G8 (106) Females, centre units D, E, and F (office staff)

G9 (97) JMM centre unit A

G10 (101) JMM centre unit B

G11 (80) JMM centre unit C

G12 (142) JMM centre unit D
Company $M$ Smaller numbers and the fact that staff employees worked in no less than 33 centres precluded definition of adequate groups by supervisory grade, centre, and marital status as in company G. Only sex and the length of the period of the data distinguished the following four study groups:

M1 (140) All male staff in continuous employment 1 October 1957 to 30 September 1959 and who were not absent for whatever cause for more than 65 days in either accounting year

M2 (83) As above, but female staff

M3 (71) As M1 above but in continuous employment 1 October 1952 to 30 September 1959

M4 (27) As M3 above, but female staff

Groups M3 and M4 provide material for mainly the longitudinal study.

Government service Observations relate exclusively to (permanent) clerical staff in two departments over 1959. Groups were distinguished only by sex and department: the other classifying items used in company $\mathbf{G}$ were omitted because nearly all clerical staff were 'junior', all females were 'single', and the marital status of men was known from the records only at the time of their employment. The four study groups were:

SC1 (71) Males in continuous employment in department X during 1959 who were not absent for more than 65 days

SC2 (83) As above, but females

SC3 (369) As SC1 but in department Y

SC4 (371) As SC3, but females

As already emphasized, homogeneity of each study group for known important variables is essential. This has produced a larger number of smaller study groups for analysis rather than a smaller number of larger, though inevitably more heterogeneous ones. As well as ensuring validity and allowing certain inter-group comparisons, the approach adopted has produced an additional dimension, viz., the consistency of many results over the study groups can be examined and, if established, this must add weight to any general conclusions drawn.

The 20 study groups defined above are used (a) to test the observations against expectation on several plausible hypotheses which might govern the distribution of one-day and two-day absences, and $(b)$ to study the effect on short-term absence of certain important factors. To facilitate interpretation of the results under $(a)$ it is necessary to deal first with $(b)$. This is done below and in the following paper; the analyses under $(a)$ are in a third paper (Froggatt, 1970d) which completes the study. In these papers the result of a statistical test is described as 'significant' 
only when it was likely to occur by chance in less than $5 \%$ of trials.

\section{Results}

Effect of age and length of service on short-term absence

Regression analysis Age and length of service are two simple factors, almost universally recorded, which are known to affect sickness absence, and the former also may affect short-term absence. They are, however, interdependent (Table 3). Their combined and independent effects on one-day and twoday absences are measured here by multiple linear regression using the following notation:

Let $\bar{y}_{1}=$ the mean number of one-day absences per person in a study group for the period of the data;

$\overline{\mathbf{x}}_{1}=$ the mean age in years of members of that study group at the start of the period;

$\overline{\mathbf{x}}_{2}=$ the mean length of service (in completed years) of members of that study group on the same date;

$b_{1}=$ the estimated partial regression coefficient of $y_{1}$ on $x_{1}$;

$b_{2}=$ the estimated partial regression coefficient of $\mathrm{y}_{1}$ on $\mathrm{x}_{2}$; and

$c=$ the estimated constant.

TABLE 3

Analysis of Correlations between Age AND LENGTH OF SERVICE

\begin{tabular}{l|c|c|c}
\hline Group & $\begin{array}{c}\text { No. } \\
\text { of pairs }\end{array}$ & $\begin{array}{c}\text { Correlation } \\
\text { coefficient } \\
(\mathbf{r})^{\mathbf{1}}\end{array}$ & $\mathrm{t}$ \\
\hline G1 & 113 & 0.412 & $4 \cdot 79$ \\
G2 & 123 & 0.438 & 5.34 \\
G3 & 116 & 0.430 & $5 \cdot 12$ \\
G4 & 195 & 0.529 & $8 \cdot 67$ \\
G5 & 132 & 0.449 & $5 \cdot 76$ \\
G6 & 94 & 0.547 & 6.29 \\
G7 & 111 & 0.383 & 4.35 \\
G8 & 106 & 0.468 & $5 \cdot 38$ \\
M1 & 140 & 0.443 & $5 \cdot 83$ \\
M2 & 83 & 0.466 & 4.80 \\
SC1 & 71 & 0.866 & 14.44 \\
SC2 & 83 & 0.752 & 10.44 \\
\hline
\end{tabular}

On normal theory $P<0.001$ for all values of $t$

${ }^{1}$ The generating distributions of employees by age are reasonably symmetrical (and some are 'normal') over the range 20 to 65 years; those by length of service are bizarrely skewed because of year-to-year variation in personnel intake (Froggatt, 1967, appendix).
Then the multiple linear regression equation of the number of one-day absences $\left(y_{1}\right)$ on age $\left(x_{1}\right)$ and length of service $\left(x_{2}\right)$ can be represented by

$$
Y_{1}=c+b_{1} x_{1}+b_{2} x_{2}
$$

where $Y_{1}$ is a predicted value of the mean number of one-day absences taken by employees of age $x_{1}$ years and with length of service $x_{2}$ years. For twoday absences $y_{2}$ and $Y_{2}$ replace $y_{1}$ and $Y_{1}$ respectively. The sampling distributions of $c, b_{1}$, and $b_{2}$ are well known and their standard errors are easily computed.

One-day absences: Linear regression Estimates of $c, b_{1}$, and $b_{2}$ are given in Table 4. Six of the 14 values of $b_{1}$ (all negative) but only one value of $b_{2}$ (positive) are significant. More detailed analysis of groups G1 to G8 (Table 5) shows that the eight regression planes may be accepted as being parallel though not coincident from which the relationship of $y_{1}$ with $x_{1}$ and $x_{2}$ may be taken as not significantly different in each group though the absolute values are dissimilar. Such consistency in groups covering works personnel and staff suggests that these findings may be general to the company. The average partial regression coefficients within groups - which (Table 5) may now be used as more efficient estimates than those in any one group - are $b_{1}=0.054 \pm 0.016$ $(\mathrm{t}=-3.34$, D.F. $=987, \mathrm{P}<0.001)$ and $\mathrm{b}_{2}=$ $0.031 \pm 0.029(t=-1.05$, D.F. $=987,0.30>$ $P>0 \cdot 20)$ which confirm the associations.

Since in each of G1 to G8, $y_{1}$ was independent of $x_{2}$, this latter was omitted and regressions of $y_{1}$ on $x_{1}$ were re-calculated. Regression analysis showed that there was no significant difference in their slopes (variance ratio $=1.60, n_{1}=7, n_{2}=974$, $0.20>P>0.10$ ), though there was in their positions (variance ratio $=11 \cdot 23, \mathrm{n}_{1}=7, \mathrm{n}_{2}=974$, $P<0.001$ ), again indicating consistency of the relationship between one-day absences and age. (For full analysis see Froggatt $(1967, \mathrm{ch}$. IV).) The average regression coefficient within groups is $b=-0.062 \pm 0.014(\mathrm{t}=-4.26$, D.F. $=988$, $P<0.001)$ and the appropriate values of $c$ are given in Table 6. Table 6 also allows ranking of groups by number of one-day absences and shows JMM of works personnel (G1 and G2) and office staff (G5) to have had better attendance than JMM of works staff (G3 and G4), with the other groups intermediate. Too much should not be read into these figures since the range and distribution of ages in each group were sometimes very different.

Strictly, valid regression analysis requires the dependent variable $\left(\mathrm{y}_{1}\right)$ to be normally distributed. In no group was this so - as, measured by the statistics (Snedecor, 1946, pp. 176-7), all were positively skewed and most were lepto-kurtotic (see Froggatt, 1970d) - but in each group $\sqrt{ } y_{1}$ can be accepted as following a normal curve (Table 7). 
TABLE 4

Multiple Regression Equations for Predicted Mean Number of One-day Absences ( $Y_{1}$ ), given Age $\left(x_{1}\right)$ AND Length of Service $\left(x_{2}\right)$

\begin{tabular}{|c|c|c|c|}
\hline \multirow{2}{*}{ Group } & \multicolumn{3}{|c|}{ Estimates \pm standard errors for $\mathrm{c}, \mathrm{b}_{1}$ and $\mathrm{b}_{2}$} \\
\hline & c & $b_{1}$ & $b_{2}$ \\
\hline $\begin{array}{l}\text { G1 } \\
\text { G2 } \\
\text { G3 } \\
\text { G4 } \\
\text { G5 } \\
\text { G6 } \\
\text { G7 } \\
\text { G8 }\end{array}$ & $\begin{array}{r}5.724 \pm 1.993 \\
3.185 \pm 1.611 \\
11.980 \pm 2.554 \\
8.998 \pm 1.367 \\
7.492 \pm 1.395 \\
4.046 \pm 1.953 \\
11.978 \pm 2.180 \\
7.849 \pm 1.208\end{array}$ & $\begin{array}{ll}-0.021 & \pm 0.051 \\
+0.030 & \pm 0.038 \\
-0.094 & \pm 0.063 \\
-0.077^{1} & \pm 0.035 \\
-0.081^{1} & \pm 0.037 \\
+0.079 & \pm 0.067 \\
-0.137^{1} & \pm 0.053 \\
-0.104^{1} \pm C .040\end{array}$ & $\begin{array}{ll}-0.016 & \pm 0.099 \\
-0.130 & \pm 0.066 \\
-0.074 & \pm 0.162 \\
-0.016 & \pm 0.056 \\
+0.023 & \pm 0.064 \\
-0.175 & \pm 0.130 \\
-0.012 & \pm 0.075 \\
-0.034 & \pm 0.082\end{array}$ \\
\hline $\begin{array}{l}\text { M1 } \\
\text { M2 }\end{array}$ & $\begin{array}{l}6 \cdot 862 \pm 1.028 \\
4 \cdot 777 \pm 1 \cdot 367\end{array}$ & $\begin{array}{l}-0.102^{2} \pm 0.028 \\
+0.027 \pm 0.053\end{array}$ & $\begin{array}{l}+0.120^{1} \pm 0.058 \\
+0.064 \pm 0.180\end{array}$ \\
\hline $\begin{array}{l}\text { SC1 } \\
\text { SC2 } \\
\text { SC3 } \\
\text { SC4 }\end{array}$ & $\begin{array}{l}1.090 \pm 0.333 \\
1.605 \pm 0.455 \\
0.458 \pm 0.161 \\
1.014 \pm 0.159\end{array}$ & $\begin{array}{ll}-0.024 & \pm 0.013 \\
-0.033 & \pm 0.019 \\
+0.001 & \pm 0.003 \\
-0.009^{1} & \pm 0.004\end{array}$ & $\begin{array}{c}+0.044 \pm 0.036 \\
+0.044 \pm 0.031 \\
-\end{array}$ \\
\hline
\end{tabular}

${ }^{1}$ Significant at $\mathbf{P}=0.05$.

2Significant at $\mathbf{P}=0.001$.

TABLE 5

Analysis of Regressions in TABLe 4 (Groups G1 to G8)

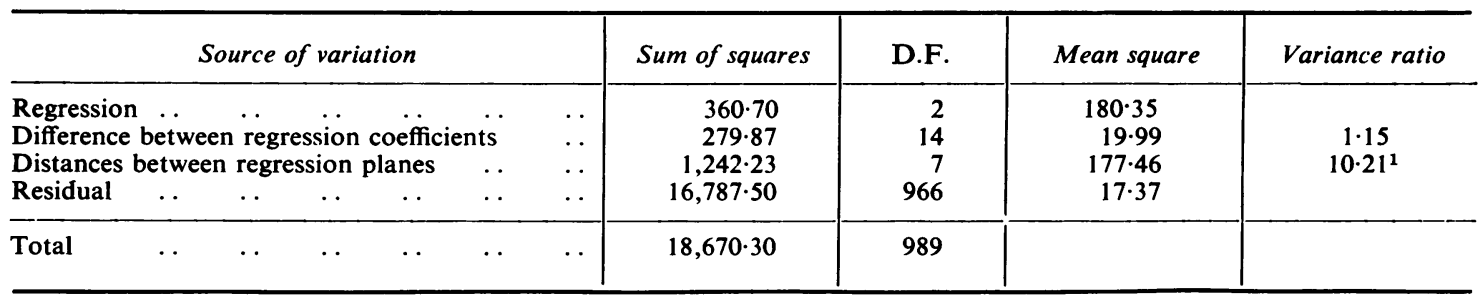

'Significant at $P=\mathbf{C . 0 0 1}$

TABLE 7

TABLE 6

ESTIMATES FOR REGRESSION CONSTANT (c) BASED ON AVERAGE WITHIN-GROUPS REgRESSION Coefficient of Number of ONE-DAY AbSENCES $\left(\mathrm{Y}_{1}\right)$ ON AGE $\left(\mathrm{x}_{1}\right)$ $\left(\mathrm{Y}_{1}=\mathrm{c}-0.062 \mathrm{x}_{1}\right)$

\begin{tabular}{c|c}
\hline Group & $\mathrm{c} \pm S E(\mathrm{c})$ \\
\hline G1 & $2.332 \pm 0.626$ \\
G2 & $1.682 \pm 0.672$ \\
G3 & $4.962 \pm 0.639$ \\
G4 & $3.091 \pm 0.622$ \\
G5 & $1.905 \pm 0.601$ \\
G6 & $3.715 \pm 0.484$ \\
G7 & $3.144 \pm 0.656$ \\
G8 & $2.747 \pm 0.480$ \\
\hline
\end{tabular}


Re-calculation of the regressions (groups G1 to G8), substituting $\sqrt{y_{1}}$ for $y_{1}$, showed $b_{1}$ to be significant in the same four groups as in Table 4 but now one value of $b_{2}$, as against none previously, is significant (group G2: $b_{2}=0.045 \pm 0.018,0.05>P>0.01$ ). Proceeding as before, first-order regressions of $\sqrt{y_{1}}$ on $\mathrm{x}_{1}$ were calculated (Table 8) but their analysis now showed significant differences in their slopes (Table 9) and so they could not be pooled. In practice, therefore, in groups G1 to G8 the choice is between describing the relationship between one-day absences and age in terms of $(a)$ eight constants and one average within-group regression coefficient, which may be imprecise because the distributions of $y_{1}$ were skewed, and $(b)$ eight different equations without such criticism but which describe the relationship in terms of the normally distributed $\sqrt{ } \mathrm{y}_{1}$ which may be less convenient to apply in practice. Individual circumstances will generally decide the choice.

One-day absences: Curvilinear regression To decide whether the relationship between one-day absences

TABLE 8

Regression Equations for Predicted SQUARE-ROOT MEANS NUMBER OF ONE-DAY Absences $\left(\sqrt{ } Y_{1}\right)$ gIVEN Age $\left(x_{1}\right)$

\begin{tabular}{c|c|c}
\hline \multirow{2}{*}{ Group } & \multicolumn{2}{|c}{$\begin{array}{c}\text { Estimates } \pm \text { standard errors } \\
\text { for } \mathrm{c} \text { and } \mathrm{b}\end{array}$} \\
\cline { 2 - 3 } & $\mathrm{c}$ & $\mathrm{b}$ \\
\hline G1 & $1.672 \pm 0.447$ & $-0.007 \pm 0.010$ \\
G2 & $1.433 \pm 0.447$ & $-0.003 \pm 0.010$ \\
G3 & $3.558 \pm 0.437$ & $-0.022^{1} \pm 0.010$ \\
G4 & $2.984 \pm 0.288$ & $-0.018^{2} \pm 0.007$ \\
G5 & $2.858 \pm 0.390$ & $-0.026^{2} \pm 0.010$ \\
G6 & $2.079 \pm 0.400$ & $+0.003 \pm 0.012$ \\
G7 & $3.543 \pm 0.469$ & $-0.029^{2} \pm 0.011$ \\
G8 & $2.792 \pm 0.299$ & $-0.026^{2} \pm 0.009$ \\
\hline
\end{tabular}

${ }^{1}$ Significant at $P=0.05$.

${ }^{2}$ Significant at $P=0.01$. $\left(y_{1}\right)$ and age $\left(x_{1}\right)$ is better represented by a curve, regressions, using the simple power series in $x_{1}$, of the form

$$
Y_{1}=c+B_{1} x_{1}+B_{2} x_{1}{ }^{2}+B_{3} x_{1}{ }^{3}
$$

where $B_{1}, B_{2}$, and $B_{3}$ are the estimated partial regression coefficients, were calculated for groups G1 to G8 using in turn $y_{1}$ and the normally distributed variate $\sqrt{y_{1}}$. Step-by-step testing (Quenouille, 1952, p. 95 et seq.) showed improvement due to quadratic or cubic terms to be significant in only one group (the cubic term in G7) but even here it was less than the linear effect (Froggatt, 1967, Table IV. 19 and 20). Linear regression, therefore, adequately describes the (weak) relationship between number of one-day absences and age.

Two-day absences: Linear regression Proceeding as above, now substituting two-day $\left(\mathrm{y}_{2}\right)$ for one-day absences $\left(y_{1}\right)$, gives results (Table 10) indicating that the number of two-day absences was independent of both age and length of service. Transforming $y_{2}$ to a normal variate for more valid analyses was impossible because the mode of the distribution was generally in the zero frequency class (Froggatt, 1970d); from the experience of one-day absences, however, use of the untransformed measure probably allows reasonably valid conclusions.

Ranking groups by values of $\mathrm{c}$ in Table 10 shows, as for one-day absences, that works personnel (G1 and G2) had the 'best' record.

Longitudinal study: One-day and two-day absences The conclusions from the analyses above can be questioned on the ground that the data are from cross-sectional groups. The organizations could not, however, provide data over a sufficiently long period to allow adequately sized homogeneous groups to be studied: even if they could have, the results may not have been applicable to all employees since the cohorts would have been restricted to 'stayers', thus becoming more highly selected as the period increased. Nevertheless some results can be presented.

TABLE 9

ANALYSIS OF REgRESSIONS IN TABLE 8

\begin{tabular}{|c|c|c|c|c|c|c|c|c|c|c|c|}
\hline \multicolumn{8}{|c|}{ Source of variation } & \multirow{2}{*}{$\begin{array}{c}\begin{array}{c}\text { Sum of } \\
\text { squares }\end{array} \\
14 \cdot 29 \\
17 \cdot 30\end{array}$} & \multirow{2}{*}{$\begin{array}{r}\text { D.F. } \\
1 \\
7\end{array}$} & \multirow{2}{*}{$\begin{array}{c}\begin{array}{c}\text { Mean } \\
\text { square }\end{array} \\
2.47\end{array}$} & \multirow{2}{*}{$\begin{array}{c}\begin{array}{c}\text { Variance } \\
\text { ratio }\end{array} \\
2 \cdot 72^{1}\end{array}$} \\
\hline $\begin{array}{l}\text { Overall regression } \\
\text { Difference between re }\end{array}$ & . & $\ddot{n}$ coeffic & cients & $\begin{array}{l}\cdots \\
\cdots\end{array}$ & $\begin{array}{l}\cdots \\
\cdots\end{array}$ & $\begin{array}{l}\cdots \\
\cdots\end{array}$ & $\begin{array}{l}\cdots \\
\cdots\end{array}$ & & & & \\
\hline $\begin{array}{l}\text { Sum of regressions } \\
\text { Residual }\end{array}$ & $\begin{array}{l}\cdots \\
\cdots\end{array}$ & $\begin{array}{l}. \\
.\end{array}$ & $\begin{array}{l}\cdots \\
\cdots\end{array}$ & $\begin{array}{l}\cdots \\
\cdots\end{array}$ & $\begin{array}{l}\cdots \\
\cdots\end{array}$ & $\begin{array}{l}\cdots \\
\cdots\end{array}$ & $\begin{array}{l}\cdots \\
\cdots\end{array}$ & $\begin{array}{r}31 \cdot 59 \\
883 \cdot 90\end{array}$ & $\begin{array}{r}8 \\
974\end{array}$ & 0.91 & \\
\hline Total .. & . & . & . & $\ldots$ & . & . & . & 915.49 & 982 & & \\
\hline
\end{tabular}

Significant at $\mathbf{P}=0.01$. 
TABLE 10

Multiple Regression Equations for Predicted Mean Number of Two-day Absences $\left(Y_{2}\right)$ given Age $\left(x_{1}\right)$ and Length of Service $\left(x_{2}\right)$

\begin{tabular}{|c|c|c|c|}
\hline \multirow{2}{*}{ Group } & \multicolumn{3}{|c|}{ Estimates \pm standard errors for $\mathrm{c}, \mathrm{b}_{1}$, and $\mathrm{b}_{2}$} \\
\hline & c & $b_{1}$ & $\mathbf{b}_{\mathbf{2}}$ \\
\hline $\begin{array}{l}\text { G1 } \\
\text { G2 } \\
\text { G3 } \\
\text { G4 } \\
\text { G5 } \\
\text { G6 } \\
\text { G7 } \\
\text { G8 }\end{array}$ & $\begin{array}{l}1.007 \pm 0.724 \\
0.811 \pm 0.470 \\
2.209 \pm 0.930 \\
2.481 \pm 0.756 \\
2.676 \pm 0.761 \\
1.603 \pm 0.899 \\
2.882 \pm 1.047 \\
1.472 \pm 0.518\end{array}$ & $\begin{array}{l}-0.001 \pm 0.018 \\
+0.004 \pm 0.011 \\
+0.003 \pm 0.023 \\
-0.009 \pm 0.019 \\
-0.009 \pm 0.020 \\
+0.009 \pm 0.031 \\
-0.017 \pm 0.025 \\
+0.014 \pm 0.017\end{array}$ & 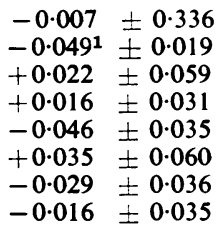 \\
\hline $\begin{array}{l}\text { M1 } \\
\text { M2 }\end{array}$ & $\begin{array}{l}1.174 \pm 0.359 \\
0.842 \pm 0.718\end{array}$ & $\begin{array}{l}-0.010 \pm 0.010 \\
+0.024 \pm 0.028\end{array}$ & $\begin{array}{l}+0.008 \pm 0.020 \\
+0.023 \pm 0.080\end{array}$ \\
\hline $\begin{array}{l}\text { SC1 } \\
\text { SC2 } \\
\text { SC3 } \\
\text { SC4 }\end{array}$ & $\begin{array}{l}0.490 \pm 0.151 \\
0.256 \pm 0.285 \\
0.214 \pm 0.088 \\
0.220 \pm 0.089\end{array}$ & $\begin{array}{r}0.000 \pm 0.010 \\
+0.004 \pm 0.011 \\
0.000 \pm 0.002 \\
+0.002 \pm 0.002\end{array}$ & $\begin{array}{c}-0.013 \pm 0.027 \\
+0.008 \pm 0.018 \\
\text { - }\end{array}$ \\
\hline
\end{tabular}

1Significant at $\mathbf{P}=0.05$.

Groups M3 and M4 comprise individuals employed for seven consecutive years (1953-59). Over this period the mean annual number of one-day absences $\left(\bar{y}_{1}\right)$ decreased in both groups, more regularly for males (M3) than for females (M4), while the mean annual number of two-day absences $\left(\bar{y}_{2}\right)$ showed no strong trend; and generally the variances followed the means (Table 11). Testing $\bar{y}_{1}$ for 1953 (the highest value) in groups M3 and M4 against $\bar{y}_{1}$ for each of the other years in turn showed the former to be significantly greater only than $\bar{y}_{1}$ in $1957(\mathrm{t}=2.35$, D.F. $=140,0.05>\mathrm{P}>0.02)$ and in $1958(t=2.55$, D.F. $=140,0.02>P>0.01)$ for M3; while there were no significant differences in either group between the value for $\bar{y}_{2}$ in 1953 compared to $\bar{y}_{2}$ for any other year. These results support those of the regression analysis above.
The decrease in the mean number of one-day absences over only seven years is unlikely to be due to any effect of age per se; it could be due, however, inter alia either to the disproportionately higher number of one-day absences taken in low length of service grades (because the company started in Belfast in 1950, most employees in 1953 - the first year of the data and with the highest value of $\bar{y}_{1}-$ had 0,1 , or 2 years' length of service) not uncovered by the regression analysis, or to general 'environmental' causes. To discriminate between these hypotheses larger numbers from company $G$ were examined by selecting, from groups $G 1$ to $G 7$, the 717 (males) in continuous employment over 1955-58 and from these identifying two groups who had respectively 0 or 1 , and 2 or more completed years of service on 1 January 1955 . Table 12 shows an

TABLE 11

Annual Mean Number of One-day $\left(\bar{y}_{1}\right)$ and Two-day $\left(\bar{y}_{2}\right)$ Absences, and their Variances $\left(\sigma^{2}\right)$ FOR TWO GROUPS OF EMPLOYEES OVER 7 YEARS

\begin{tabular}{|c|c|c|c|c|c|c|c|c|}
\hline \multirow{2}{*}{ Year } & \multicolumn{4}{|c|}{ Group M3 } & \multicolumn{4}{|c|}{ Group M4 } \\
\hline & $\bar{y}_{1}$ & $\sigma^{2}$ & $\bar{y}_{2}$ & $\sigma^{2}$ & $\bar{y}_{1}$ & $\sigma^{2}$ & $\overline{\mathbf{y}}_{2}$ & $\sigma^{2}$ \\
\hline $\begin{array}{l}1953 \\
1954 \\
1955 \\
1956 \\
1957 \\
1958 \\
1959\end{array}$ & $\begin{array}{l}2.85 \\
2 \cdot 39 \\
2 \cdot 32 \\
2.08 \\
1.93 \\
1.85 \\
2.08\end{array}$ & $\begin{array}{l}6.96 \\
4 \cdot 87 \\
6 \cdot 05 \\
3.91 \\
3 \cdot 70 \\
3 \cdot 79 \\
3 \cdot 59\end{array}$ & $\begin{array}{l}0.44 \\
0.59 \\
0.62 \\
0.56 \\
0.58 \\
0.41 \\
0.45\end{array}$ & $\begin{array}{l}0.54 \\
0.73 \\
1.10 \\
0.82 \\
0.73 \\
0.45 \\
0.48\end{array}$ & $\begin{array}{l}3.70 \\
2.93 \\
3.56 \\
3.00 \\
3.04 \\
3.04 \\
2.70\end{array}$ & $\begin{array}{l}6 \cdot 52 \\
9 \cdot 15 \\
5 \cdot 26 \\
4 \cdot 85 \\
3 \cdot 81 \\
4 \cdot 58 \\
5 \cdot 45\end{array}$ & $\begin{array}{l}1.07 \\
1.04 \\
1.11 \\
0.89 \\
0.96 \\
0.93 \\
0.85\end{array}$ & $\begin{array}{l}1.61 \\
2.19 \\
0.80 \\
0.95 \\
0.96 \\
0.84 \\
0.67\end{array}$ \\
\hline
\end{tabular}


TABLE 12

AnNual Mean Numbers of One-day ABSENCES $\left(\bar{y}_{1}\right)$, AND THEIR VARIANCES, For Two Groups of MALE EMPLOYeES (IN Company G) OVer 4 Years

\begin{tabular}{c|cc|cc}
\hline \multirow{3}{*}{ Year } & \multicolumn{3}{|c}{ Length of service on 1 January 1955 } \\
\cline { 2 - 5 } & $\begin{array}{c}\text { Men with 0 or 1 year } \\
(n=134)\end{array}$ & \multicolumn{2}{c}{$\begin{array}{c}\text { Men with 2+ years } \\
(n=583)\end{array}$} \\
\cline { 2 - 5 } & $\bar{y}_{1}$ & $\sigma^{2}$ & $\bar{y}_{1}$ & $\sigma^{2}$ \\
\hline 1955 & 3.537 & 10.262 & 3.087 & 9.829 \\
1956 & 4.000 & 11.814 & 3.144 & $9 \cdot 110$ \\
1957 & 2.903 & 9.231 & 2.719 & 6.084 \\
1958 & 2.784 & 8.682 & 2.521 & $6 \cdot 154$ \\
\hline
\end{tabular}

inverted $U$ trend for the values of $\bar{y}_{1}$ over 1955-58 in both groups with a peak at 1956 and consistently higher year-specific values of $\bar{y}_{1}$ for the shorter length of service group. (This latter finding is not unequivocal and may be due to the confounding effect of age, short length of service employees being on average younger.) Testing - by comparing $\bar{y}_{1}$ for 1955 with $\bar{y}_{1}$ for each of the other three years in turn shows no significant differences in the (smaller) shorter length of service group, but in the (bigger) longer length of service group $\overline{\mathbf{y}}_{1}$ for 1955 is significantly greater than $\bar{y}_{1}$ for $1957(t=2 \cdot 23, D . F .=$ $1164,0.05>P>0.02)$ and $1958(t=3.41$, D.F. $=$ $1164, P<0.001)$. These results suggest that 'environmental causes' as well as some effect of short length of service may contribute to the trend in Table 11.

\section{Discussion and summary}

A full discussion will appear in the final paper (Froggatt, 1970d); the following is a summary.

The literature suggests that shorter-term absences are negatively associated with age (Wyatt, 1945; London Transport Executive, 1956; Gordon et al., 1959), more so with works personnel than staff (London Transport Executive, 1956). The present data on one-day, but not on two-day, absences accords with this - though here the association is more marked for staff (all groups except G1 and G2) - and the regression analyses show that the relationship can be considered as not dissimilar for the study groups within each organization even though the absolute values are different. This indicates that some facet of age operates independently of length of service, sex, supervisory grade, and marital status. One-day absences have many causes ranging from ill-health to frank malingering, and without subdividing them by 'cause' (which was impossible) one cannot study the relationships further. Asking personnel the 'cause' of their shortterm absence - as tried in pilot interviews - produced many patently spurious answers and bred antagonism, and furthermore the reason for a particular short-term absence is rarely single, and attempted classification by 'cause' would have been frequently arbitrary. In subsequent papers I will examine the association between short-termabsences and other recorded variables (Froggatt, 1970c), and the form of the frequency distributions of shortterm absences (Froggatt, 1970d) in an effort further to elucidate causation.

The findings above are of little executive importance. The association of one-day absences with age, though consistent and statistically significant, is very weak. Linear regression, though it describes the relationship, leaves never less than $90 \%$ of the variation in one-day absences unexplained (Table 13). The higher average annual number of one-day absences per person for those with (very) short length of service (Tables 11 and 12) is not definitely established because of the confounding age effect (short length of service employees being younger on average): even if it were real the difference is too small to warrant executive attention. The findings, however, are important to the tests of the distributions. Theoretically, the groups for these tests should be homogeneous for variables with a (known) effect on short-term absence other than the variable accounted in each hypothesis tested. The very weak or non-significant association of short-term absences with age and length of service means that in practice sub-grouping by these factors is unnecessary.

TABLE 13

Data on Multiple Correlation Coefficients (R) FOR NUMBER OF ONE-DAY ABSENCES $\left(Y_{1}\right)$ With Age $\left(\mathrm{x}_{1}\right)$ ANd Length of Service $\left(\mathrm{x}_{2}\right)$

\begin{tabular}{c|cc}
\hline Group & $\mathbf{R}$ & $\begin{array}{l}1-\mathbf{R}^{2} \\
(\%)\end{array}$ \\
\hline G1 & 0.040 & $99 \cdot 2$ \\
G2 & 0.177 & 96.9 \\
G3 & $0 \cdot 178$ & 96.8 \\
G4 & $0 \cdot 195$ & 96.2 \\
G5 & $0 \cdot 197$ & 96.1 \\
G6 & 0.150 & 97.8 \\
G7 & 0.267 & 92.9 \\
G8 & 0.258 & 93.3 \\
\hline
\end{tabular}

The references for this paper will appear at the end of Part III in the October 1970 issue of the Journal.

Received for publication October 13, 1969. 